doso en la 1

ar ejemplos a

is funcionalidac uso, dependiende encarnan los conceptos detr por e $\Lambda$ influ
$\mathrm{Pe}$ infin:

Las formas $d r$ oceso de sig ialidad .

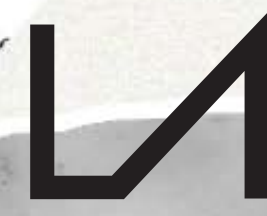

R E V I S A
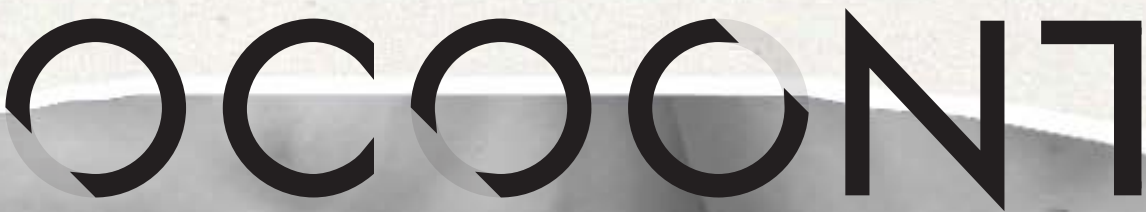

D $E$

No $6 \cdot 2019 \cdot$ ISSN 2386-8449

"El producto del diseñador es un proyecto, el estado previo de un objeto", Entrevista con Norberto Chaves, por Fernando Infante

El papel de la investigación y la teoría en diseño. Una conversación abierta, por Fernando Infante y María Jesús Godoy

UT PICTURA POESIS

Abandonar la escritura. Poesía experimental y manifiesta, Ignacio Gómez de Liaño

PANORAMA: FILOSOFÍA DEL DISEÑO Sección coordinada por Fernando Infante y María Jesús Godoy

Pensar el diseño, Fernando Infante y María Jesús Godoy (Coordinadores)

TEXTOS INVITADOS

Estatus y estado del điseño más allá del objeto, Pedro Medina Reinón

Mar de Nubes, Cuerpo de Cristal, Dionisio González

ARTÍCULOS

Understanding Design Aesthetics beyond Functional Beauty accounts, Lucía Jiménez Sánchez

Estética y diseño industrial: debates y controversias, Joan M. Marín

Del ornamento al delito. El diseño y la sociedad en Charles Baudelaire y Adolf Loos, Jorge López Lloret

When is Architecture not Design? Saul Fisher

Diseño y habitabilidad: una aproximación basada en los lenguajes de patrones, Antonio Hidalgo Pérez

Marcel Breuer: un diseñador global. Experiencias en el ámbito de la vivienda prefabricada, Salvador J. Sanchis, Ignacio Peris y Pedro Ponce Diseño y artes escénicas: el papel de Oskar Schlemmer en Das Triadische Ballett y la actualidad de la Bauhaus, Milagros García Vázquez Lo performativo en prácticas de arte y diseño actuales vinculadas a procesos de innovación social. El caso de La Venezia che non si vede y de La borda, Tània Costa Gomez

Articulaciones de la estética y el diseño. El caso de la evaluación a partir de la investigación dirigida en la carrera de diseño escénico de la Universidad de las Artes de Cuba, Mara Rodríguez Venegas y Xiomara Romero Rojas

SUPLEMENTO

El diseño, la ciudad y un lápiz de labios, Mercedes Espiau, Mar García Ranedo y Alejandro Rojas mas. 


\section{UつCつCNTE}

No $6 \cdot 2019 \cdot \operatorname{ISSN} 2386-8449 \cdot$ DOI 10.7203/LAOCOONTE.5.15381

https://ojs.uv.es/index.php/LAOCOONTE/index

COORDINACIÓN EDITORIAL

Anacleto Ferrer (Universitat de València)

Francesc Jesús Hernàndez i Dobon (Universitat de València)

Fernando Infante del Rosal (Universidad de Sevilla)

SECRETARÍA DE REDACCIÓN

Lurdes Valls Crespo (Universitat de València)

Vanessa Vidal Mayor (Universitat de València)

COMITÉ DE REDACCIÓN

Tamara Djermanović (Universitat Pompeu Fabra), Rosa Fernández Gómez (Universidad de Málaga), Anacleto Ferrer (Universitat de València), Ilia Galán (Universidad Carlos III), Ana María García Varas (Universidad de Zaragoza), María Jesús Godoy (Universidad de Sevilla), Fernando Infante del Rosal (Universidad de Sevilla), Miguel Ángel Rivero (Universidad de Sevilla), Miguel Salmerón (Universidad Autónoma de Madrid), Gerard Vilar (Universitat Autònoma de Barcelona).

COMITÉ CIENTÍFICO INTERNACIONAL

Rafael Argullol* (Universitat Pompeu Fabra), Luis Camnitzer (State University of New York), José Bragança de Miranda (Universidade Nova de Lisboa), Bruno Corà (Università di Cassino), Román de la Calle* (Universitat de València), Eberhard Geisler (Johannes Gutenberg-Universität Mainz), José Jiménez* (Universidad Autónoma de Madrid), Jacinto Lageira (Université Paris 1 Panthéon-Sorbonne), Bernard Marcadé (École Nationale Supérieure d'Arts de Paris-Cergy), Elena Oliveras (Universidad de Buenos Aires y Universidad del Salvador), Pablo Oyarzun (Universidad de Chile), Francisca Pérez Carreño* (Universidad de Murcia), Bernardo Pinto de Almeida (Faculdade de Belas Artes da Universidade do Porto), Luigi Russo (Università di Palermo), Georges Sebbag (Doctor en Filosofía e historiador del surrealismo), Zoltán Somhegyi (University of Sharjah, United Arab Emirates), Robert Wilkinson (Open University-Scotland), Martín Zubiria (Universidad Nacional de Cuyo). *Miembros de la Sociedad Española de Estética y Teoría de las Artes, SEyTA

\begin{tabular}{lll}
\hline DIRECCIÓN DE ARTE & REVISIÓN DE TEXTOS & TRANSCRIPCIÓN DE TEXTOS \\
El golpe. Cultura del entorno & Antonio Cuesta & Álvaro G. Serna
\end{tabular}

(cc) BY Excepto que se establezca de otra forma, el contenido de esta revista cuenta con una licencia Creative Commons Atribución 3.0 España, que puede consultarse en http://creativecommons.org/licenses/by/3.0/es/deed.es

EDITA

\section{SEyTA.}

CON LA COLABORACIÓN DE

\begin{tabular}{|c|c|c|c|}
\hline $\begin{array}{l}\text { VNIVERSITAT } \\
\text { B VALENCIA } \\
\text { Institut te Creativitat } \\
\text { | |nnovacions Educatives }\end{array}$ & $\begin{array}{l}\text { VNIVERSITAT } \\
\text { IE ÖVALENCIA Departament de Filosofia }\end{array}$ & 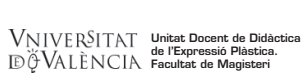 & \\
\hline $\begin{array}{l}\text { DEPARTAMENTO DE ESTÉTICA } \\
\text { E HISTORIA DE LA FLLOSOFIA }\end{array}$ & $\frac{\text { UAW }}{\frac{\text { UNIVRSSIDAD AUTONOMA }}{\text { DE MADRID }}}$ & $\begin{array}{l}\text { Universitat Autònoma } \\
\text { de Barcelona }\end{array}$ & $\begin{array}{l}\text { VNiVERSiDAD } \\
\text { Departamento de Filosofia, Lógica y Estética }\end{array}$ \\
\hline
\end{tabular}

LAOCOONTE aparece en los catálogos: 


\section{LつCつCN7E}

"Cuanto más penetramos en una obra de arte más pensamientos suscita ella en nosotros, y cuantos más pensamientos suscite tanto más debemos creer que estamos penetrando en ella".

G. E. Lessing, Laocoonte o los límites entre la pintura y la poesía, 1766.

Vo hay cól.

létodo, de pen.

:ión en general. Ith

zar la forma para el $\mathrm{n}$.

eptual por las orígenes

la, el objeto, la exposición

storia, porque existe en el $\mathrm{m}$

das sus raíces. Desde alli cc _. panoram

n conceptual y donde el émencia del con 'iseñado, como es el a al objeto y el di $\begin{array}{ll}\text { igen } \mathrm{de}^{\text {to }} \text { la inmer } & \text { tolvidada, o comc } \\ \text { trozo de madera ar }\end{array}$ a manera dorm comunicar ene nundo. Seguin? sngo en manos te el método $C$ les. A partir c teria prima $\mathrm{p}_{\mathbf{c}}$

'xto se puede:

¿ño, en proyea

amientos de $\mathrm{u}$

a conscie-

.)

en la publicación jue "plos de la impor te las nalidades porqu ura un ${ }^{2}$ diendo de qui zenerar $\mathrm{u}$ ción de nr? lne

in-

n-

is.

le http:,

le crear visualidades. A partir de.

ellas la propia materia prima para un en que desde un texto se puede generar $u_{11}$ i

Pensar en diseño, en proyección de nue

posibles comportamientos de una colecti

presente como una consciencia del hecho que estamos elaborando, significac

nuestro entorno (..)

Cardoso, R. C. Rafael. (2014). Design para um mundo complexo. Sãc asil: Cosac Naify. 


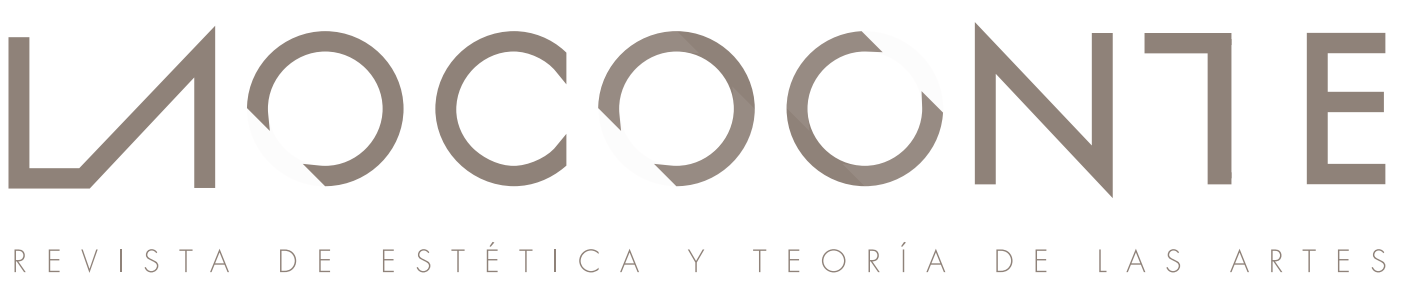

$\mathrm{N}^{\circ} 6 \cdot 2019$

PRESENTACIÓN

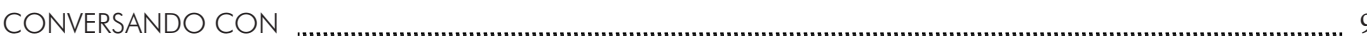

"El producto del diseñador es un proyecto, el estado previo de un objeto", Entrevista con Norberto Chaves,

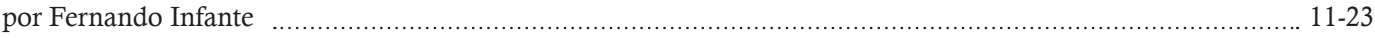

El papel de la investigación y la teoría en diseño. Una conversación abierta, por Fernando Infante

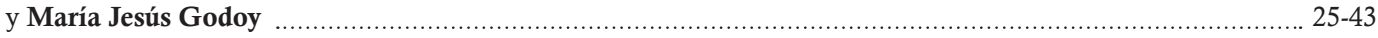

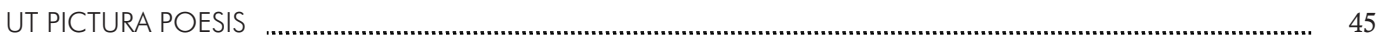

Abandonar la escritura. Poesía experimental y manifiesta, Ignacio Gómez de Liaño ................................................ 47-95

Imágenes de Laocoonte n. 6, de Isadora Gonzaga ................................................................................................... 96-97

PANORAMA

FILOSOFÍA DEL DISEÑO

Pensar el diseño, Fernando Infante y María Jesús Godoy (Coordinadores) .............................................. 101-105

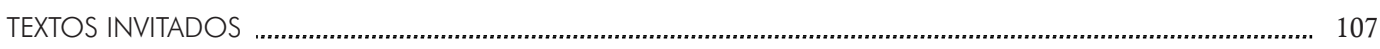

Estatus y estado del diseño más allá del objeto, Pedro Medina Reinón . ................................................... 109-125

Mar de Nubes. Cuerpo de Cristal, Dionisio González .............................................................................. 127-133

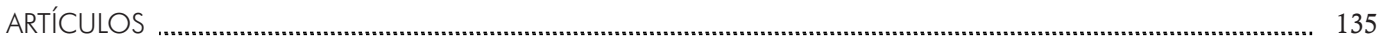

Understanding Design Aesthetics beyond Functional Beauty accounts, Lucía Jiménez Sánchez ................. 137-149

Estética y diseño industrial: debates y controversias, Joan M. Marín _...................................................... 150-164

Del ornamento al delito. El diseño y la sociedad en Charles Baudelaire y Adolf Loos, Jorge López Lloret ... $165-182$

When is Architecture not Design? Saul Fisher ……............................................................................. 183-198

Diseño y habitabilidad: una aproximación basada en los lenguajes de patrones, Antonio Hidalgo Pérez ...... 199-215

Marcel Breuer: un diseñador global. Experiencias en el ámbito de la vivienda prefabricada,

Salvador José Sanchis, Ignacio Peris y Pedro Ponce

Diseño y artes escénicas: el papel de Oskar Schlemmer en Das Triadische Ballett y la actualidad de la Bauhaus, Milagros García Vázquez

Lo performativo en prácticas de arte y diseño actuales vinculadas a procesos de innovación social.

El caso de La Venezia che non si vede y de La borda, Tània Costa Gomez

Articulaciones de la estética y el diseño. El caso de la evaluación a partir de la investigación dirigida en la carrera de diseño escénico de la Universidad de las Artes de Cuba, Mara Rodríguez Venegas

y Xiomara Romero Rojas

SUPLEMENTO 
Walter Gropius. La vida del fundador de la Bauhaus, Jorge Martínez Alcaide

¿Qué significa pensar la política desde la estética? Àger Pérez Casanovas

Ideologías estéticas en los orígenes de la pintura moderna, José Luis Plaza Chillón 300-303

Sobre a estética, Luis Carlos Pereira

Músicas populares. Sociedad y territorio: Sinergias entre investigación y docencia, Mar Aleixandre Badenes.

307-309

La necesidad de la mirada antropológica sobre la literatura, Pablo de Benito David

A propósito de Chandler, o la novela policíaca como tratado filosófico, Juan Evaristo Valls Boix

Videre aude!, Anacleto Ferrer

La inaplazable memoria del dolor y el sufrimiento, Antonio Notario Ruiz

La alargada sombra de la pintura, Raquel Baixauli

Sondear la maravilla, Juan Evaristo Valls Boix

... Y lo sabes, Marc Hernández Montoro

Arqueologías de la modernidad en las artes. Ensayo estético, Carlota Fernández-Jáuregui Rojas

Estética de la Instalación, Luis Cemillán Casis

La Herencia de otra época, María Jesús Godoy Domínguez

Del Theatrum Mundi al Gran Vidrio, Miguel Salmerón Infante

Imágenes de Isadora Gonzaga.

Fotografía de portada de Tamara Djermanovic intervenida por Isadora Gonzaga.

Los coordinadores de la sección Panorama: Filosofia del diseño agradecen

a Antonio Molina Flores su colaboración. 


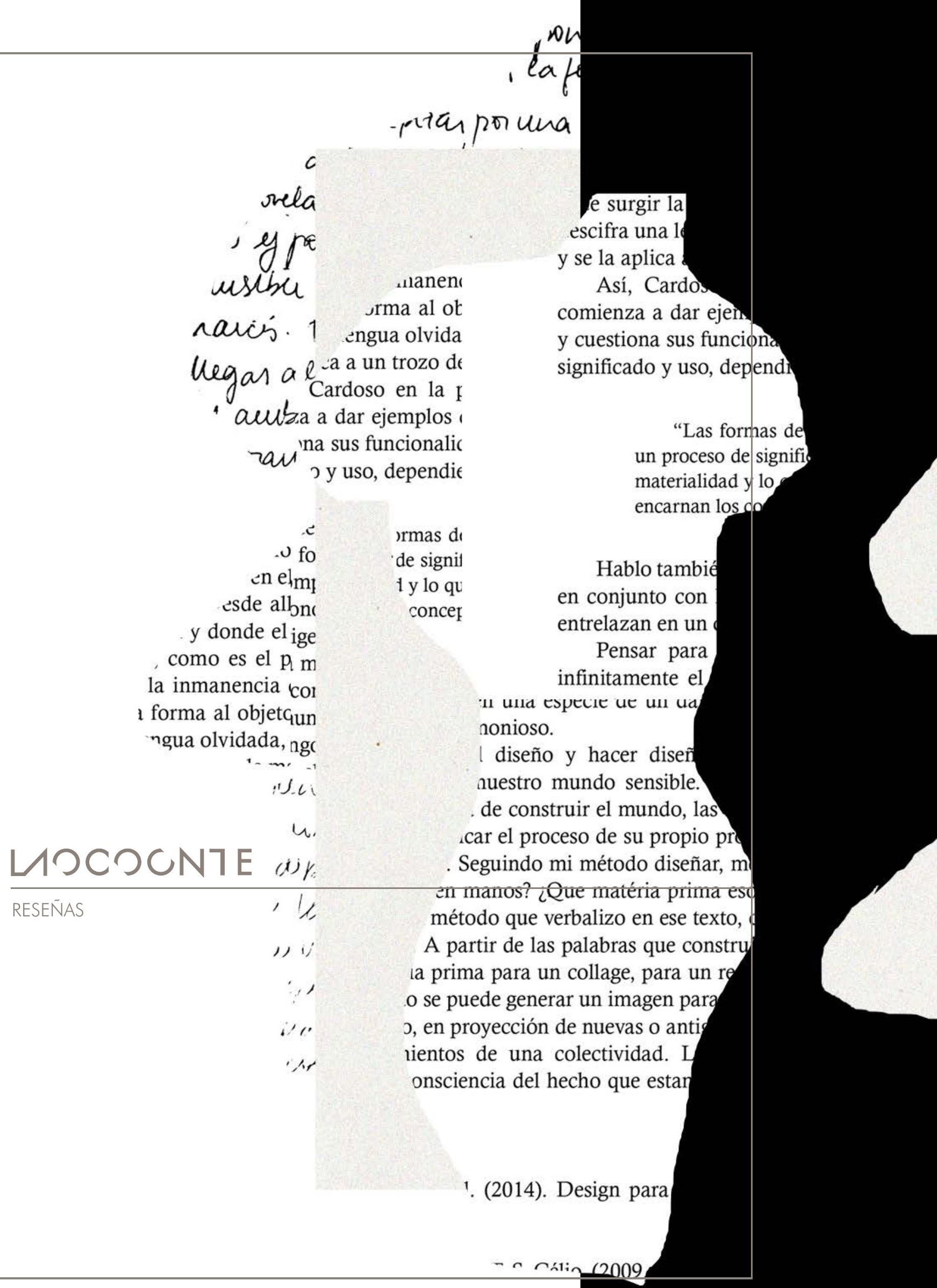




\title{
Arqueologías de la modernidad en las artes. Ensayo estético
}

\author{
Carlota Fernández-Jáuregui Rojas*
}

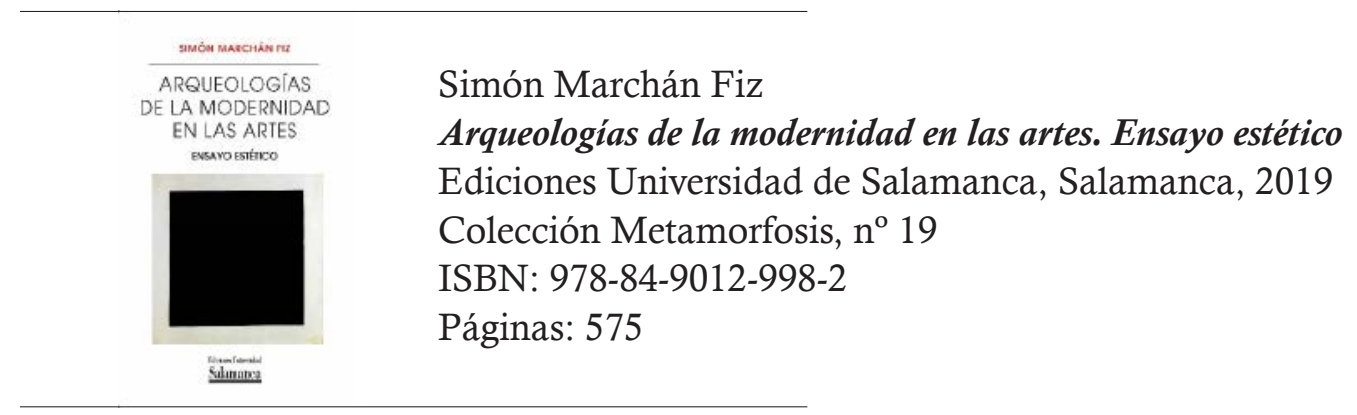

Llegará el día, decía Virgilio en sus Geórgicas, en que el labrador halle, al trabajar la tierra con el arado, las ruinas sepultadas de otra época y contemple entonces admirado "sobre las abiertas tumbas gigantescas osamentas". Son muy pocos los autores capaces de sobrevolar con una visión sinóptica las ruinas de la modernidad en las artes y llevar a cabo una labor arqueológica y retrospectiva con tal conocimiento que permita descubrir y ordenar desde el presente los fragmentos y los estratos históricos, teóricos y simbólicos sobre los que éstas se alzan. Pero más difícil todavía es encontrar quien, lejos de contemplar la modernidad como un paisaje detenido en sus relaciones y en sus momentos, sepa filtrarse e implicarse con generosidad por los desplazamientos internos de sus formas y describir la composición rítmica y dinámica de sus sedimentos. A tan valioso empeño podía sólo acceder un reconocido maestro como Simón Marchán Fiz, construyendo una obra de indudable referencia en la poética topológica de la modernidad y sus ruinas.

La monumental labor arqueológica que el profesor Marchán Fiz emprende en este Ensayo estético está compuesta por textos que, publicados entre 1974 y 2019, son ahora cuidadosamente reunidos y reelaborados. A lo largo de sus páginas, el autor no se detiene únicamente en el hallazgo de los yacimientos de la modernidad artística anclados al momento auroral de su instancia enunciativa sino, más bien, en descubrir los movimientos que trazan esas urnas y tegumentos bajo los estratos de la historia a través de sus "horizontes de posibilidad" y en el desbordamiento y extensión de sus propias figuras, pues natural es de la ruina el no ser nunca primera, sino siempre alzada -ruinas renacentistas, barrocas, románticas, modernas, etc.- sobre el/lo original inalcanzable. Este principio, que a nuestro parecer sostiene estructural y argumentalmente el libro, está en conexión con las paradojas mismas de lo nuevo, expuestas por Hans Robert Jauss en "Tradición literaria y conciencia actual de la modernidad", a saber, el dilema deícticamente insorteable de que ahora ya no es ahora y, por tanto, que lo nuevo es sólo aquello que se separa constantemente de sí mismo. Si con Baudelaire descubrimos que sólo la Nada es nueva -“Au fond de linconnu pour trouver du nouveau!"-, este 
proceso puede quizá encontrarse reflejado en el arco temporal y conceptual que Marchán Fiz dibuja entre la disolución de la forma artística romántica en la modernidad y la disolución que experimenta en la abstracción y en el caos de las vanguardias: "La modernidad acaba confrontándose consigo misma en cuanto recluye cada actualidad en el propio referente y la empuja a una imparable antigüedad" (p. 30). Lo nuevo, podríamos decir, sintetizando la vieja Querelle aquí rememorada, es la desaparición del futuro haciéndose pasado.

En sintonía con la idea anterior, destacaremos en lo que sigue dos hilos que, como tramas principales del libro, entretejen su estructura y su sentido: acontecimiento y desplazamiento. El primero remite a la accidentalidad de lo moderno, en el doble sentido que el autor encuentra tanto en las Lecciones sobre estética de Hegel, donde lo sustancial se contrapone a lo accidental, como en El pintor de la vida moderna de Baudelaire con su oposición de lo fugaz (relativo-circunstancial) a lo ideal (eterno-invariable) y, el segundo, atiende a la "historia efectual" (Wirkungsgeschichte) e "historia conceptual" (Begriffsgeschichte) del arte, es decir, "como una elección reflexiva a partir de las condiciones de posibilidades artísticas que ofrece la historia moderna, supeditada a las condiciones y a los intereses de cada presente" (15). Con ello, Marchán Fiz trasciende, desestabiliza y remueve el detenido acontecimiento con la idea del desplazamiento, una "dinámica de las transformaciones" que se abre hermenéuticamente en lo que denomina los tres "horizontes de posibilidad" de las prácticas artísticas en la modernidad que, a su vez, se corresponden con las tres grandes secciones en que se divide el libro: "El estallido de los referenciales y la quiebra de la representación", "La sublimación en la abstracción" y los "Nuevos pensamientos para los objetos y las imágenes". Si en el primero aborda la pérdida de identificación referencial que sucede entre la imagen artística, su ideal y la realidad (desde la disolución del Clasicismo hasta el Cubismo), en el último examinará el desquiciamiento semiótico y semántico entre el objeto o el hecho artístico y la "situación", dinámica e intercambiable, en la que éste se encuentra (Duchamp y el ready-made, la estética del desperdicio, el Dadaísmo, etc.).

Podemos así afirmar que la idea del efecto -tómese aquí el término en su jerga billarística- es causante de la transformación de un accidente estático (la historia conclusa de los acontecimientos en cuanto hechos artísticos que caen, literalmente, delante de nuestros ojos) en un desplazamiento temporal y formal de las genealogías y discontinuidades, y que ello provocará "una expansión de las artes" en "direcciones imprevisibles" cuyo correlato será la correspondiente extensión en la definición misma del arte (253). Así, por un lado, si la belleza fugitiva y relativa que clama la modernité realiza un primer desplazamiento en lo que el autor denomina el "desbordamiento de lo bello" -planteado en el capítulo "La fealdad reta a la belleza en la pintura y la escultura" (67-99)-, por otro lado, la experiencia moderna sobre la pérdida de lo que llamábamos un aurático el/lo original, desembocaría en un segundo desplazamiento hacia la búsqueda de unos orígenes antropológicos, aquí representados en la querencia primitivista del arte según autores como Gauguin, Einstein o Picasso en su retorno hacia formas míticas y rituales -"Las nostalgias de lo primitivo" (181-197)-, por un lado, y en su vuelta, por otro, a los fenómenos naturales y las sensaciones que claman autores como Cézanne o Matisse en una especie de "protovisión" que pone en suspenso la percepción y la sensación - "El retorno a los fenómenos en la pintura moderna" (101-130)-, mediante la oscilación fenomenológica entre lo que el autor denomina la tendencia "autocéntrica" de la percepción hacia las formas y la tendencia "alocén- 
trica" hacia la luz y el color (121-122). Esta oscilación constituiría el efecto activador por el cual un acontecimiento artístico y cultural concreto (la vuelta a los fenómenos) se manifiesta en un desarrollo histórico a partir de una serie de relaciones existentes "entre la figura y el fondo en el Impresionismo, de la luz y del color o del color en el Postimpresionismo o los modos de aparición del objeto en Cézanne" (122). Por ello, el autor propone la existencia de dos caras en la modernidad, que reúnen en su formulación componentes estáticos (accidentales) y dinámicos (deslizamientos): una "accidentalidad exterior" (vuelta a los fenómenos) y una "accidentalidad interior" (de los simbolismos y surrealismos en su retorno antropológico al "otro", a lo interior animal, a lo primitivo ritual, etc.). De este modo, asoman a lo largo del libro términos que implican no sólo el hallazgo de un "yacimiento", una "ruina" o una "quiebra" sino, más bien, la "cartografía" o "arqueología" de los "deslizamientos" y transferencias de aquello que se desborda, que rebasa y que rebosa, que se ramifica y metamorfosea. Quizá porque una de las lecciones que se desprenden de la historia de la Estética es que los hombres estamos destinados a tener que hacer algo con lo bello, aquello que sólo podemos soportar, en términos rilkeanos, transformándolo en otra cosa, emplazándolo a otra época, o desplazándolo hacia otro lugar. ¿Será ese mismo desplazamiento el que motive la "belleza de la indiferencia", compañera de la angustia que causa todo lo que no parece reversible, que trazaría la línea desde el fragmento barroco, la alegoría y las naturalezas muertas (477) hasta Duchamp (466)?

No sólo las rupturas, los desgastes y excedentes motivan nuevos desarrollos -del mismo modo que, en términos freudianos, lo reprimido aflora en su repetición-; también las carencias crean -a manera de contrapaso- la emulación por el arte de aquello mismo que lo destruye y disuelve en cada momento. Así, "el artista moderno", sentado en la roca de su ahora vacío, "a pesar de y precisamente por esta carencia", desarrolla una dependencia de su época, escribe Marchán Fiz, mayor que en los historicismos "pues su modo radical de ser histórico, prendado de cada actualidad, auspicia una hipóstasis del presente" (31). Si con Baudelaire se instauraba en la conciencia poética el Tiempo destructor del Ideal, y con Bergson el Instante anegaba el interior de la percepción en el Sujeto, cabría encontrar un mismo gesto destructor en la poética de la velocidad y la estética de las máquinas (ferrocarriles, aviones, automóviles) y en las prácticas artísticas del tiempo moderno (fotografía, danza y, después, cine) que localizara la fuente de su placer en el displacer de no poder detener el instante, ese que un día fue tan bello. A este proceso dedica el autor el capítulo "La percepción artística dinámica en la pintura, la escultura y la fotografía" (131-180) donde estudia el modo en el que la "percepción estática tradicional es complementada o sustituida", en un nuevo desplazamiento o deslizamiento, "por una percepción dinámica, cinemática", cuyo acontecimiento-efecto habría de encontrarse en "los ritmos que imprimen en nuestras vidas las máquinas y la ciudad, promovida por los objetos móviles que invaden los nuevos paisajes industriales y urbanos" (133). Esta nueva percepción de la realidad y de la naturaleza hará del arte un medio para ver (con los desarrollos artificiales y fantasmales de la fotografía y la cinematografía) aquello incluso que el ojo no ve; es decir, que una agudísima sensibilidad y percepción, agitada y excitada cada día con una suerte de estímulos nuevos, nos lleva sin embargo, en nuevo contrapaso, a querer ver más allá de lo que vemos en la Naturaleza gracias al Arte, adentrándonos en aquella búsqueda al fondo de lo desconocido, nuevo ahora para nuestros ojos y nuestros sentidos, que desembocará en la sustitución de la visión por la concepción en Apollinaire 
en su deriva hacia el cubismo y al arte conceptual (243 y ss.). Este mismo nuevo clima de la modernidad será el que conducirá, según el autor, a las prácticas futuristas, constructivistas y, a través de combinaciones sinestésicas de luz, velocidad y rugido de motores, a la abstracción: "En estas pinturas [se refiere a la serie de 1912 sobre $L a$ velocidad del automóvil de Giacomo Balla] los elementos del vehículo, en particular las ruedas en cuanto condensaciones retóricas, se desintegran en fragmentos", intentando una imposible "representación simultánea de estadios sucesivos del movimiento" que, gracias a múltiples efectos lumínicos y de líneas oblicuas que parecen emular la velocidad del objeto móvil, provocan su desmaterialización "hasta bordear los umbrales de la abstracción" (147). La misma ansiedad que provoca en Monet, Renoir o Pisarro el cambio atmosférico a lo largo de una misma jornada, o el causado por la sucesión de las estaciones, se traslada en el intento de "captar espacialmente la simulación del movimiento" mediante la expresividad del cuerpo humano, sea en acciones suspendidas (Degas o Muybridge) o dinámicas (cronofotografías de Marey o en las danzas de Fuller) y ese intento gestual crearía en torno a la obra de arte tanto la abstracción (nuevamente, por la desmaterialización que provoca el movimiento a través de superposiciones, transparencias y ritmos en las obras de van Gogh, Russolo o Balla) como el Cubismo, entendido como un dar vueltas a un mismo objeto para reconstruir las sucesivas apariencias en la duración de la visión - "Meditaciones estéticas' sobre el cubismo y el futurismo con sus fugas" (199-254)-. El Cubismo, con su serpentina danza alrededor del objeto, sería también efecto de otro deslizamiento, caracterizado como "rehabilitación de lo sensible", es decir, "una sensibilización hacia la materia y hacia una nueva "cultura de los materiales"”, que llevará al "ready-made de Marcel Duchamp y del object trouvé dadaísta surrealista” (252-253).

Desplazamiento y accidentalidad se estrechan especialmente en las mencionadas "nostalgias de lo primitivo", donde "los artefactos y los objetos rituales de los "pueblos primitivos' se inscriben en una estética del acontecimiento que se gesta en el transcurso de una temporalidad; en ella los cambios de funciones y significados impulsan nuevos puntos de vista, nuevos pensamientos, aquel 'extrañamiento' duchampiano, espacio-temporal y semántico, tal vez irrecuperable, de lo que ha sido desterritorializado" (196). De igual modo, Picasso es representado en su "voluntad agresora, disgregadora, impertinente, resistente” ('297) estrechándose su figura a la del Nietzsche de la II Intempestiva, capaces ambos de subirse a las ruinas y de mirar por encima de ellas: contra la historia, por encima de la historia, más allá de ella. El pintor es, en efecto, retratado en este capítulo - "Un artista moderno intempestivo: P. Picasso" (255-297)- en relación al ademán nietzscheano en continua transgresión, soledad y resistencia hacia sus contemporáneos; en su fortaleza; en la creación de discontinuidades a través de la intertextualidad y diálogo con el arte antiguo y clásico y en su proteica pluralidad de estilos.

Si, tal como planteábamos, el artista moderno era capaz de perseguir aquello mismo que destruía su arte (gesto de radical, bellísima y congruente destrucción, por otra parte, también muy nietzscheano), la sección central del libro, dedicada a la abstracción, demuestra cómo un mismo impulso antirrealista y antinaturalista desemboca abstraído en las formas y, a fuerza de introducirse enajenadamente en ellas, abre el espacio abstracto, como un gesto de retorno hacia la Idea, vuelta quizá a aquel Ideal que en Baudelaire impidiera el Spleen, alcanzado ahora mediante los procedimientos de idealización y estetización que acompañan el trabajo de abstracción: si lo nuevo, 
proponíamos, era aquello que se escinde continuamente de sí mismo, lo abstracto podría igualmente definirse como lo que se separa o aísla de todas sus determinaciones accidentales. Vuelta entonces al binomio de Hegel, ahora desde el fin del arte, para encontrar en lo abstracto-abstraído (lo sustancial disuelto) el principio de todo arte. De ahí, según el recorrido por el que nos lleva Marchán Fiz - "El 'principio abstracción' en sus poéticas aurorales" (301-342)-, que Kandisnky reclamara una "nueva época", Malévich "el grado cero" y Mondrian "la nueva imagen", algo en realidad no ajeno a la nueva dispositio que parecían exigir Duchamp o el arte Merz, y que haría de la colocación una nueva manera de ver las cosas, en sintonía con la idea de procedimiento, según la terminología de Shklovsky (384): se trata entonces de una "abstracción instauradora" capaz de simbolizar y realizar nuevos mundos. El "giro espiritual" del arte abstracto en Kandinsky tiene que ver con el "giro verbal" del pensamiento en Mallarmé, Saussure y Shklovski, que Marchán Fiz encontrará en la vuelta de la arquitectura sobre sí misma: el arte abstracto tiende al poder del lenguaje para invocar -en su sentido primero de incipit- la palabra en la mente del oyente como si se tratara de un impulso corporal, un signo gráfico y un sonido (306ss.). Porque, podemos afirmar, la música es el efecto de la poesía que hace devenir el acontecimiento del cuadro en el desplazamiento de la abstracción. Porque entrar en el cuadro es entrar en el poema, y entrar en el poema es entrar en la mente, donde se halla la Idea, lo más parecido a la Nada. Y, de nuevo, es la Nada el único verdadero principio.

El shock que Benjamin encontrara en la experiencia poética moderna de Baudelaire nos parece similar al momento de revelación que ante la Nada abstracta experimentó Kandinsky, según el relato del propio pintor sobre el que lúcidamente reflexionará Marchán Fiz (313): "Y de repente vi por primera vez un cuadro [El almiar de heno de Monet]. Que esto era un almiar de heno, me lo aseguraba el catálogo. No lo podía reconocer. Este no reconocer me era penoso [...] Sentí claramente que el objeto faltaba en este cuadro. Pero inconscientemente se desacreditaba también el objeto como elemento imprescindible del cuadro". Este "amor a última vista", por utilizar la expresión benjaminiana, que sucede aquí entre el pintor y el objeto, se transformará en el adiós a primera vista, podríamos decir, que caracterizaría la experiencia artística de la inobjetividad y del ready-made con respecto a la disolución del objeto y al extrañamiento de su "situación" mediante una nueva "inscripción" o, respectivamente, con la "objetividad potenciada" y la "descontextualización de las citas" en la nueva arquitectura -aspectos tratados en los capítulos "La "inobjetividad" como grado cero de las formas (343-384); "La transfiguración artística de los objetos en la estela de una intuición kantiana" (445-482), y "La arquitectura como crítica de su lenguaje y la abstracción potenciada" (403-442)-.

La liberación del objeto -cuya forma "no modal" referiría Roland Barthes en El grado cero de la escritura, obra invocada por Marchán Fiz en su correlato con la pintura y la arquitectura (374 y 405-406) y desde la que, creemos, podría definirse un nuevo modus, no marcado, para lo modernus - llevará a Duchamp a la "anestética" o "indiferencia visual" (466-471) y a Malévich a encontrar "la construcción de las formas a partir de la nada" rompiendo con la forma en cuanto dialéctica cerrada o clausurada -de nuevo resulta pertinente (y seductor) apuntar la existencia de un paralelo con la deconstrucción que se efectúa sobre el estructuralismo lingüístico-: "Pero yo me he transformado en el cero de las formas y he ido más allá del 0-1" (Malévich apud Marchán 322). Y, siguiendo la teoría de los desplazamientos, lo que podríamos llamar el 
contrapaso de la abstracción será -por efecto de la "función poética" que después definiera Jakobson-, la construcción o, posteriormente, el arte concreto.

Así como la ruina entrega su cuerpo a la naturaleza, que con sus fuerzas la invade y con sus raíces la abraza, dándole un nuevo lugar y sentido, así la obra de Marchán Fiz evita el "pensamiento binario" sobre el arte y la clasificación estática y absoluta de las vanguardias, para conducirnos a un espacio abierto de significación, dominado por los "entrecruzamientos", las "líneas de fuerza", las tensiones y "confrontaciones irresueltas" (542) que mueven con sus "horizontes de posibilidad" estas admirables Arqueologías sin fin.

Las arqueologías aquí trazadas son la huella de una modernidad viva y en movimiento, mudada entre los capítulos que la sostienen, como si se tratara de las fases de metamorfosis que componen la imagen de una siempre sucesiva mariposa. El Ensayo estético de Marchán Fiz, fruto de una labor realizada a lo largo de una vida dedicada a la docencia, a la escritura y al pensamiento es, a su vez, imago de otras "Metamorfosis": las de la excelente colección dirigida durante más de dos décadas por José Luis Molinuevo en el área de Estética y Teoría de las Artes de la Universidad de Salamanca quien, con este último título, pasa el testigo a Domingo Hernández Sánchez como director de la colección. 


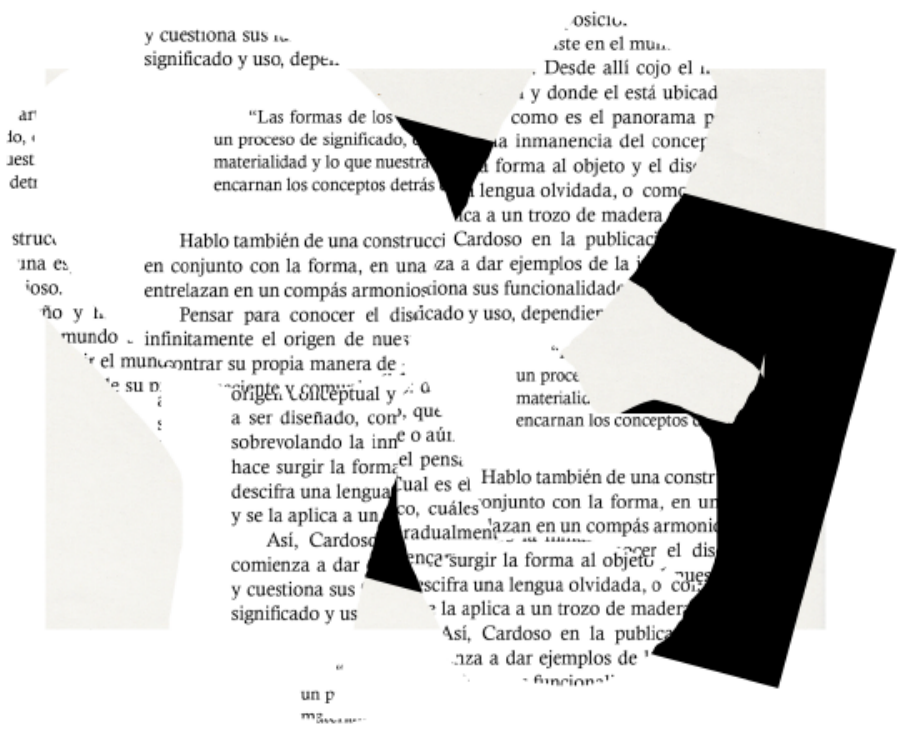

"Lo impreso exige una humildad de espíritu por cuya falta muchas de las bellas artes se tambalean ahora en experimentos de autoconciencia y sensiblería. No hay nada simple ni aburrido en lograr una página transparente. La ostentación vulgar es el doble de fácil que la disciplina".

Beatrice Warde, The Crystal Goblet, or why printings should be invisible (1930)

"El diseño que es objetivo, comprometido con el bien común, bien compuesto y delicado, constituye la base del comportamiento democrático".

Josef Müller-Brockmann, Grid and Design Philosophy (1981) 

EDITA

\section{SEyTA.}

SOCIEDAD ESPAÑLAA
DE ESTETICA Y TEORIA DE LAS ARTES

CON LA COLABORACIÓN DE

\begin{tabular}{|c|c|c|}
\hline 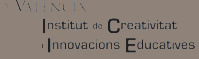 & $\begin{array}{l}\text { VNIVIRSIIA } \\
\text { In VVIIINCI Departament de Filosofia }\end{array}$ & 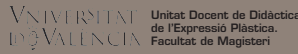 \\
\hline $\begin{array}{l}\text { TitTicA } \\
\text { SoFFA }\end{array}$ & 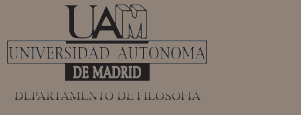 & $\begin{array}{l}\text { UAB } \\
\text { Universitat Autònoma } \\
\text { de Barcelona }\end{array}$ \\
\hline
\end{tabular}

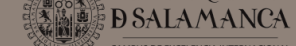

https://ojs.uv.es/index.php/LAOCOONTE/index 